\title{
A Percepção da Experiência de Primeiro Aprisionamento em uma Unidade Prisional
}

\author{
Milena de Andrade Bahiano ${ }^{1}$ \\ ${ }^{1}$ Universidade Federal de Sergipe, SE, Brasil. \\ Geovanna Santana de Souza Turri ${ }^{1}$ \\ ${ }^{1}$ Universidade Federal de Sergipe, SE, Brasil. \\ André Faro ${ }^{1}$ \\ ${ }^{1}$ Universidade Federal de Sergipe, SE, Brasil.
}

\begin{abstract}
Resumo: Este estudo buscou compreender a experiência do primeiro aprisionamento no sistema penitenciário e identificar os comportamentos adaptativos desencadeados a partir desse contexto estressor. A amostra foi composta por 61 detentos, divididos em dois grupos: G1 (internos provisórios, $n=42$ ) e G2 (internos sentenciados, $n=19$ ). Utilizou-se um questionário sociodemográfico e criminal, além da técnica de evocação livre de palavras com os termos indutores "prisão" e "futuro". As evocações foram analisadas com o auxílio do software OpenEvoc e os demais dados com o SPSS. Os resultados mostraram que, a partir do termo indutor "prisão", o conteúdo evocado pelos dois grupos revelou a instituição como um lugar difícil de se viver, de adoecimento e de sofrimento físico e psicológico. Já a partir do termo "futuro", observou-se que ambos apresentaram expectativas positivas para o recomeço de suas vidas em liberdade, tais como ter responsabilidade, fé, estar próximo da família e sentir-se reinserido socialmente por meio do trabalho e dos estudos. Em resumo, mesmo diante do impacto do aprisionamento, foi perceptível no conteúdo evocado a existência de fatores considerados protetivos na adaptação do indivíduo à vida na prisão. Finalmente, acredita-se que, a partir do discurso evocado, profissionais da saúde e de áreas afins possam identificar fatores de risco e de proteção que deem suporte à atenção e aos cuidados prestados à saúde física e mental dos detentos ou em condição de primeiro encarceramento.
\end{abstract}

Palavras-chave: Adaptação, Enfrentamento, Prisioneiro, Prisão, Psicologia.

\section{The Perception of the Experience of First Imprisonment in a Prison Unit}

\begin{abstract}
This study sought to understand the experience of the first imprisonment in a penitentiary system and to identify adaptive behaviors triggered by this stressful context. The sample consisted of 61 inmates who were divided into two groups: remand prisoners (G1, $\mathrm{n}=42)$ and convicted prisoners $(\mathrm{G} 2, \mathrm{n}=19)$. Data was collected by means of a sociodemographic and criminal questionnaire and by the free evocation technique, based on the inductive terms "prison" and "future". Sociodemographic data was analyzed using the SPSS and evocations were analyzed using the OpenEvoc software. The content evoked from the term "prison" denoted the prison facility as a difficult place to live for both groups, causing illness and physical and psychological suffering. As for the the term "future", both groups showed positive expectations for the resumption of their lives in freedom, including having responsibility, faith, being close to their families, and being socially reinserted through work and studies. Despite the impact of the imprisonment, the content evoked in prisoners' reports indicated the existence of protective factors in the adjustment to the life in prison. These evoked discourses may function as instruments for professionals from health and related areas to identify risk and protection factors that support the physical and mental healthcare provided for incarcerated individuals or those experiencing first imprisonment.
\end{abstract}

Keywords: Adaptation, Coping, Prisioner, Prison, Psychology. 


\title{
La Percepción de la Experiencia de Primer Encarcelamiento en una Unidad Penitenciaria
}

\begin{abstract}
Resumen: Este estudio pretende comprender la vivencia de primer encarcelamiento en el sistema penitenciario e identificar los comportamientos adaptativos que se desencadenan en este contexto estresante. La muestra fue compuesta por 61 detenidos, los cuales se dividieron en dos grupos: G1 (internos provisionales, $n=42$ ) y G2 (internos sentenciados, $n=19$ ). Se utilizó el cuestionario sociodemográfico y criminal, y la técnica de evocación libre de palabras con los términos inductores "prisión" y "futuro". Para el análisis de las evocaciones se utilizó el software OpenEvoc, y para los demás datos el SPSS. Los resultados mostraron que, en lo que se refiere al término inductor "prisión", el contenido evocado por ambos grupos reveló la institución como un lugar difícil de vivir, de enfermedad y de sufrimiento físico y psicológico. En cuanto al término "futuro", ambos grupos presentaron expectativas positivas para reanudar sus vidas en libertad, tales como tener responsabilidad, fe, estar cerca de la familia y sentirse inserido socialmente por medio del trabajo y de los estudios. En resumen, a pesar del impacto del encarcelamiento se observa la existencia de factores considerados protectores para la adaptación del individuo a la vida en la prisión. Se espera que estos resultados puedan ayudar a profesionales de la salud y de áreas afines a identificar factores de riesgo y de protección para la atención y cuidados prestados a la salud física y mental de los prisioneros o en condición de primer encarcelamiento.
\end{abstract}

Palabras clave: Adaptación, Enfrentamiento, Prisionero, Prisión, Psicología.

\section{Introdução}

No Brasil, o Levantamento de Informações Penitenciárias (Infopen) estimou que até meados de 2016 havia 689.510 pessoas custodiadas em estabelecimentos administrados pelas secretarias estaduais de Administração Prisional e Justiça (Santos, 2017). Os dados também indicaram que $40 \%$ da população prisional brasileira era composta por presos em regime provisório, ou seja, aqueles que aguardavam, detidos, a decisão da justiça sobre sua condenação ou soltura. No mesmo levantamento, o Infopen avaliou que $78 \%$ das unidades prisionais funcionavam acima de sua capacidade populacional (Santos, 2017). Tais estatísticas corroboram o que já é noticiado por veículos de comunicação e demonstram a precariedade das condições de vida e saúde nos presídios, a morosidade da justiça, além de políticas públicas ineficientes na garantia dos direitos previstos na Lei de Execução Penal (assistência à saúde, educação, trabalho, assistência material, jurídica e assistência religiosa).

A restrição à liberdade é impactante, seja no primeiro aprisionamento, seja em casos de reincidência. A adaptação ou readaptação à vida na prisão prediz quais hábitos e rotinas adquiridos em liberdade deverão ser reajustados e aspectos cognitivos e comportamen- tais têm papel importante nesse processo, podendo ou não facilitar o ajustamento psicológico à condição de detento (Afonso, 2012; Colombaroli, 2013; Gonçalves \& Gonçalves, 2012). A constância com que situações estressantes no presídio ocorrem tem caráter cumulativo, expondo as pessoas presas a maiores chances de acometimento por doenças físicas e mentais, além de impor nível de passividade considerado mórbido diante da falta de autogerenciamento da vida (Carr \& Umberson, 2013; Colombaroli, 2013).

A partir da entrada na prisão, o indivíduo terá as necessidades básicas gerenciadas pelo Estado e pela instituição penal, como saúde, alimentação, banho, higienização das celas, vestimentas, contato com familiares e até mesmo a vida sexual. O espaço de convivência reduzido e amplamente controlado somado a uma rotina de privações, preocupações, ócio, agressividade e violência quase imutáveis, torna o cárcere um ambiente extremamente hostil e estressante (Afonso, 2012; Colombaroli, 2013). Para além da adaptação às regras do sistema prisional, os indivíduos têm ainda que se adaptar às regras da cultura carcerária, o que demanda esforço ainda maior para enfrentar a vida na prisão (Colombaroli, 2013; Gonçalves \& Gonçalves, 2012; Pinheiro \& Cardoso, 2011). 
A adaptação é vista como um processo que evoca modificações e alterações comportamentais no indivíduo, em busca do melhor nível de ajustamento a um determinado contexto estressor (Afonso, 2012), sendo esse um processo individual, em que cada pessoa reagirá de modo diferente às situações limitantes e estressantes da vida privada de liberdade (Carvalho, Lecat, \& Sendas, 2016). No sistema prisional, a adaptação ocorre por meio da identificação e compreensão das regras estabelecidas pela instituição penal e pelos próprios detentos, além da maneira como o indivíduo lida com esses códigos de conduta. Portanto, para que haja um reajustamento da pessoa presa a essa situação indutora de estresse, seu comportamento terá que se modificar para tentar alcançar um nível minimamente saudável de acomodação ao meio prisional (Afonso, 2012).

$\mathrm{O}$ primeiro aprisionamento, particularmente, representa uma mudança repentina no modo de vida do indivíduo devido ao afastamento abrupto do núcleo familiar e social. A experiência de se viver na prisão e as expectativas e incertezas criadas quanto às demandas judiciais e ao futuro, dentro e fora do cárcere, expõem o apenado a um risco maior de acometimento por perturbações mentais comuns (Araújo, Nakano, \& Gouveia, 2009; Pinheiro \& Cardoso, 2011). Isso tende a desencadear sintomas significativos de depressão, ansiedade e agressividade, mais presentes nos indivíduos encarcerados pela primeira vez do que em presidiários reincidentes e antigos na prisão (Colombaroli, 2013; Constantino, Assis, \& Pinto, 2016; Pinheiro \& Cardoso, 2011). Assim, a pessoa presa pela primeira vez se encontra em maior vulnerabilidade, sendo mais suscetível ao adoecimento mental e a reações psicológicas motivadas por alta exposição a estresse agudo e cronicizante (Ahmad \& Mazlan, 2014).

A psicologia da saúde estuda o estresse e sua relação com o adoecimento, assim como as estratégias de enfrentamento utilizadas pelo indivíduo diante do contato com elementos estressores (Alves \& Eulálio, 2011; Schwarzer \& Schutz, 2003). Portanto, compreender o estado mental do indivíduo encarcerado em condição de primeira privação de liberdade amplia as possibilidades de intervenção no campo da prevenção e promoção à saúde e minora os agravos psicológicos decorrentes da reclusão (Araújo et al., 2009; Colombaroli, 2013; Constantino et al., 2016; Pinheiro \& Cardoso, 2011).

Na Colômbia, o Instituto Nacional Penitenciario y Carcelario (Inpec) elaborou um programa de assistência psicológica às pessoas presas, o objetivo do Inpec é fornecer a esse grupo minoritário intervenções e acompanhamento psicológico especializado, tendo em vista o retorno desses indivíduos à sociedade (Uribe-Rodríguez, Martínez-Rodríguez, \& López-Romero, 2012). A partir de ações como essa, a psicologia da saúde efetiva sua contribuição à saúde mental das pessoas presas e os benefícios podem ampliar possibilidades de adaptação frente à adversidade.

Em 2014, os Ministérios da Saúde e da Justiça publicaram a Lei Interministerial que instituiu a Política Nacional de Atenção Integral à Saúde das Pessoas Privadas de Liberdade no Sistema Prisional (PNAISP) (Portaria GM/MS no 01, 2014), um grande avanço na atenção à saúde das pessoas presas. O PNAISP garante o direito de acesso da população sob custódia do Estado e privada de liberdade aos serviços básicos de atenção à saúde (Portaria GM/MS no 01, 2014; Schultz, Dias, Lewgoy, \& Dotta, 2017).

A saúde da população prisional é uma questão de saúde pública, e diversos autores têm apontado a necessidade de pesquisas que explorem essa temática e contribuam para a elaboração de políticas públicas e a diminuição do sofrimento mental e físico dentro e fora das prisões (Colombaroli, 2013; Gois, Santos, Silveira, \& Gaudêncio, 2012). Nesse cenário, a ação da psicologia da saúde, em um trabalho multidisciplinar, centra-se na prevenção e cuidados em saúde, visando a redução do mal-estar mesmo em ambientes considerados nocivos (Alves \& Eulálio, 2011; Remor, 1999; Schwarzer \& Schutz, 2003). No panorama atual, a prisão mostra-se um espaço de penalização, violações dos direitos humanos e adoecimento. Assim, não é disposto ao apenado um ambiente que favoreça sua reintegração social (Damas \& Oliveira, 2013).

Com as deficiências na atenção à saúde e nos programas nas áreas de educação, trabalho e cultura, muitas pessoas em primeira reclusão acabam reincidindo criminalmente e retornado à prisão com problemas jurídicos e comprometimento da saúde ainda maiores (Araújo et al., 2009; Pinheiro \& Cardoso, 2011), isso demonstra que, investigar esse grupo é relevante para que tal parcela da população tenha visibilidade no âmbito da atenção à saúde mental e nas ações promovidas no sistema prisional.

O sofrimento vivenciado no cárcere causa impacto ainda sobre o comportamento do indivíduo, podendo acarretar, além de reincidências, também abuso de substâncias psicoativas e mortes por suicídio na prisão (López-Pérez, Deeprose, \&Hanoch, 2018). Logo, enten- 
der o processo de adaptação do indivíduo com tempo de encarceramento, prolongado ou não, permite a identificação de estratégias de enfrentamento oportunas para o manejo da tensão e estresse vivenciados na prisão. Ademais, o período de encarceramento, às vezes turbulento, pode vir a comprometer o futuro da pessoa presa, bem como suas relações sociais e familiares, quando retornar ao convívio em sociedade (Carvalho et al., 2016; Cooper \& Livingston, 1991).

No presente estudo, buscou-se coletar, a partir de evocações livres de palavras, o modo como os internos percebem suas experiências na prisão e como pensam seu futuro. Dessa maneira, procurou-se compreender, a partir da perspectiva da pessoa privada de liberdade, a repercussão da vivência do primeiro aprisionamento, além de apontar e compreender estressores e comportamentos adaptativos que se manifestam nesse contexto.

\section{Participantes}

\section{Método}

Este estudo foi desenvolvido no Conjunto Penal de Paulo Afonso, na Bahia, com homens em primeira experiência de privação de liberdade e que cumpriam pena no regime fechado ou provisório. A unidade prisional se configura como de média segurança e possui capacidade para 412 internos; no momento da coleta de dados, estavam sob custódia 389 internos. A amostra foi selecionada por conveniência, de caráter intencional $^{1}$, e a pesquisa foi realizada em dois pavilhões do presídio, escolhidos a partir do quantitativo de internos em primeiro aprisionamento. Desse modo, 93 internos foram identificados em tal condição, dos quais 25 (26,9\% da amostra) se recusaram a participar da pesquisa, quatro $(4,3 \%)$ estavam ausentes por ter recebido alvará de soltura e outros três $(3,2 \%)$, no momento da entrevista, encontravam-se com problemas psiquiátricos, não sendo viável sua participação.

A amostra final foi composta por 61 internos em primeira experiência de aprisionamento $(65,6 \%$ da população), que consentiram sua participação no estudo e eram capazes de descrever de maneira apurada suas vivências no ambiente penitenciário. Os detentos foram organizados em dois grupos, para melhor compreensão das experiências e expectativas futuras que envolvem o processo de primeiro encarceramento: o grupo 1 (G1), com 42 internos (68,9\%) em regime provisório, ou seja, que ainda não foram julgados pela justiça, e o grupo 2 (G2), com 19 internos (31,1\%) que já foram sentenciados e cumprem pena em regime fechado na prisão.

\section{Descrição da amostra}

A média de idade dos participantes foi de 29,2 anos (Mínimo $[\operatorname{Min}]=18,0$; Máximo $[\operatorname{Max}]=63,0$; Desvio-Padrão $[D P]=10,64)$. A maior parte deles é formada por homens solteiros $(47,5 \% ; n=29)$, seguidos de casados $(34,4 \% ; n=21)$, aqueles com união estável $(14,8 \%$; $n=9)$ e os divorciados ou separados $(3,3 \% ; n=2)$. Quase metade dos detentos se autodeclarou como moreno/ pardo $(47,5 \% ; n=29)$, seguidos por brancos $(27,9 \%$, $n=17)$ e pretos $(24,6 \% ; n=15)$. O ensino fundamental foi a escolaridade mais apontada, $42,6 \%(n=26) ; 31,1 \%$ $(n=19)$ estudaram até o ensino médio, $16,4 \%(n=10)$ se autodeclararam analfabetos e apenas $9,9 \%(n=6)$ chegaram a completar o ensino superior. A maioria dos internos afirmou ter ao menos 1 filho $(65,6 \% ; n=40) \mathrm{e}$ professar alguma religião $(54,1 \% ; n=33)$. Os participantes, em geral, possuíam um tempo médio de 15,2 meses de encarceramento ( $\operatorname{Min}=1,0 ; \operatorname{Max}=7,8 ; D P=16,03$ ).

Ao analisar a amostra em grupos separados, encontramos algumas diferenças: no G1, a média de idade foi de 26,9 anos ( Min = 18,0; $\operatorname{Max}=56,0 ; D P=9,01$ ) e tempo médio de aprisionamento de 10,1 meses $(\operatorname{Min}=1,0$; $M a x=60 ; D P=9,91)$. A maior parte dos presos provisórios estudaram até $\mathrm{o}$ ensino fundamental $(47,6 \% ; n=20)$ e declararam professar alguma religião $(40,5 \% ; n=17)$. No G2, a média de idade foi de 34,3 anos (Min = 19,0; $M a x=63,0 ; D P=12,35$ ), sendo que os integrantes deste grupo estavam há aproximadamente 26,3 meses presos ( $\operatorname{Min}=2,0, \operatorname{Max}=78,0 ; D P=21,05)$. A maioria dos participantes cursou até o ensino médio $(36,9 \% ; \mathrm{n}=7)$ e declarou professar alguma religião $(57,9 \% ; n=11)$.

\section{Instrumentos}

Utilizou-se um questionário sociodemográfico inquerindo dados a respeito da idade (em anos), estado civil (solteiro, casado, união estável, separado, viúvo), filhos (sim ou não), escolaridade (ensino fundamental, médio e superior), religião (sim ou não), informações quanto ao tipo de cumprimento de pena (provisório ou sentenciado) e tempo de primeiro aprisionamento (em

\footnotetext{
${ }^{1}$ Tipos de amostras não probabilísticas, nas quais a população investigada se encontra disponível no mesmo local da entrevista e o pesquisador participa da escolha dos participantes a partir do conhecimento sobre a população estudada e objetivo da pesquisa (Cozby, 2014; Marconi \& Lakatos, 2003).
} 
meses). Também se utilizou a técnica de evocação livre de palavras, perguntando aos participantes primeiramente: "Quais são as cinco primeiras coisas ou palavras que vêm a sua mente quando ouve a palavra prisão?" e, posteriormente, "Quais são as cinco primeiras coisas ou palavras que vêm a sua mente quando ouve a palavra futuro?". A partir dos termos indutores "prisão" e "futuro", os participantes puderam evocar conteúdos que lhes vieram à mente de maneira espontânea.

Toda a coleta de dados foi realizada em salas apropriadas (parlatórios) nos respectivos pavilhões em que os internos cumpriam pena, e o tempo médio de aplicação foi de 30 minutos. No momento da entrevista, somente a pesquisadora principal e o participante estavam presentes. A coleta de dados foi realizada no período entre janeiro e abril de 2017.

\section{Procedimentos}

Este estudo está respaldado na resolução no 510/2016 do Conselho Nacional de Saúde (CNS) e foi aprovada pelo Comitê de Ética em Pesquisa com Seres Humanos da Universidade Federal de Sergipe. Em etapa anterior à coleta de dados, foi solicitado ao diretor da unidade prisional a autorização para a realização da pesquisa.

No momento da entrevista, os internos foram individualmente convidados a participar da pesquisa, bem como foram esclarecidos de que, a qualquer momento, poderiam retirar sua participação do estudo. A entrevista foi conduzida verbalmente a fim de diminuir qualquer desconforto ao interno no caso de o apenado não saber ler e/ou apresentar dúvidas quanto ao Termo de Consentimento Livre e Esclarecido (TCLE) e objetivos da pesquisa. Após a confirmação da participação no estudo, o TCLE era entregue ao agente penitenciário escalado no pavilhão onde o interno cumpria pena para que a assinatura de consentimento pudesse ser coletada e a entrevista iniciada. Os participantes não permitiram gravações em áudio ou vídeo.

\section{Análise de dados}

Para a análise descritiva dos dados sociodemográficos e criminais, utilizou-se o programa estatístico SPSS (versão 20.0) e realizou-se a análise exploratório-descritiva para obter as frequências absolutas e percentuais, limites superior e inferior, médias, medianas e desvios-padrão de todas as variáveis.

As análises das evocações foram realizadas por meio do programa computacional OpenEvoc 0.84 , que permite em seus resultados a formação de quatro casas distribuídas em quatro quadrantes (Ferrari \& Lima, 2016; Sant'Anna, 2012). O OpenEvoc é um software gratuito destinado à coleta, análise e visualização de dados. Ele pode ser encontrado em plataforma on-line (Sant'Anna, 2012) e permite analisar estatisticamente as evocações da amostra, considerando ordem e frequência das respostas. Com base nisso, define-se a importância das respostas e dos termos indutores para se construir matrizes de coocorrências.

O OpenEvoc possibilita analisar os dados resultantes de evocações coletadas e agrupadas em quadrantes a partir da frequência dos termos, da ordem média de importância e da ordem média das evocações (Ferrari \& Lima, 2016). Esses quadrantes apontam tanto a quantidade de vezes que a evocação foi lembrada quanto a prevalência de cada uma. Ao final, a análise fornece um quadro com quatro quadrantes com funções específicas, em que se encontram palavras com frequências alta e baixa, e de alta ou baixa primazia (Quadro 1).

\section{Quadro 1}

Síntese do conteúdo dos quatro quadrantes fornecidos pelo OpenEvoc.

\begin{tabular}{|c|c|}
\hline \multicolumn{2}{|c|}{ Quadro Geral de Casas do OpenEvoc } \\
\hline $\begin{array}{c}\text { Quadrante 1 } \\
\text { Fornece as palavras que } \\
\text { foram evocadas mais } \\
\text { rapidamente (menor } \\
\text { ordem média) e que } \\
\text { apresentam elevada } \\
\text { frequência (maior } \\
\text { quantidade). Em termos } \\
\text { de conteúdo, tende } \\
\text { a representar uma } \\
\text { significativa pregnância } \\
\text { do pensamento referente } \\
\text { ao objeto. }\end{array}$ & $\begin{array}{c}\text { Quadrante } 2 \\
\text { Fornece os elementos } \\
\text { que foram muito } \\
\text { mencionados (maior } \\
\text { quantidade), mas em } \\
\text { posições de maior } \\
\text { ordem média. Essas } \\
\text { evocações embasam } \\
\text { o conteúdo do } \\
\text { primeiro quadrante, } \\
\text { contribuindo para seu } \\
\text { entendimento. }\end{array}$ \\
\hline $\begin{array}{c}\text { Quadrante 3 } \\
\text { Encontram-se as } \\
\text { evocações de menor } \\
\text { frequência e menor } \\
\text { ordem de evocação. São, } \\
\text { em geral, evocações } \\
\text { importantes para um } \\
\text { grupo menor ou singular } \\
\text { na amostra, que com } \\
\text { o passar do tempo, } \\
\text { se reforçadas, podem } \\
\text { compor o grupo do } \\
\text { primeiro quadrante. }\end{array}$ & $\begin{array}{c}\text { Quadrante } 4 \\
\text { Revela as evocações } \\
\text { de maior ordem e } \\
\text { menor frequência. } \\
\text { Contém as evocações } \\
\text { menos lembradas ou } \\
\text { lembradas por último, } \\
\text { menos enraizadas nos } \\
\text { pensamentos } \\
\text { do sujeito. }\end{array}$ \\
\hline
\end{tabular}

Nota. Informações retiradas dos trabalhos de Ferrari e Lima (2016) e Sant'Anna (2012). 
Esses quadrantes são úteis para que se conheça crenças e representações sociais de determinado objeto e, assim, seja possível identificar conteúdos relacionados ao comportamento da população estudada.

\section{Resultados}

Este estudo buscou compreender como as pessoas presas pela primeira vez vivenciam o aprisionamento e quais os comportamentos adaptativos que são desencadeados nesse contexto, sendo a amostra dividida em dois grupos: G1 (internos provisórios) e G2 (internos sentenciados). Ao pedir que os detentos dissessem quais palavras lhes vêm à mente ao ouvir os termos "prisão" e "futuro", obteve-se no total 389 evocações, sendo 262 palavras evocadas pelo G1 e 127 palavras evocadas pelo G2. Para a construção do Quadro de Quatro Casas (QQC) sobre "prisão" e "futuro" do G1, foi adotado como ponto de corte para a Ordem de Evocação 2,5 e para a Frequência 2,5. Já para o G2, o QQC das evocações sobre "prisão" adotou como ponto de corte para a Ordem de Evocação 3,0 e para a Frequência 3,0. Na composição do QQC das evocações sobre "futuro", a Ordem de Evocação utilizada foi 2,0 e para a Frequência 2,0. As Tabelas 1 e 2 detalham respectivamente os conteúdos evocados sobre os termos indutores "prisão" e "futuro".

Tabela 1

Quadro geral de casas das evocações sobre a prisão em uma amostra de indivíduos em primeiro aprisionamento.

\begin{tabular}{|c|c|c|c|c|c|}
\hline \multicolumn{6}{|c|}{$1^{\circ}$ Quadrante } \\
\hline \multirow{2}{*}{\multicolumn{3}{|c|}{$\begin{array}{c}\text { Frequência > 2,5 e Classificação média < 2,5 } \\
\text { G1 }\end{array}$}} & \multirow{2}{*}{\multicolumn{3}{|c|}{$\begin{array}{c}\text { Frequência > 3,0 e Classificação média < 3,0 } \\
\text { G2 }\end{array}$}} \\
\hline & & & & & \\
\hline Enunciações & $F^{1}$ & Ord. ${ }^{2}$ & Enunciações & $\mathbf{F}$ & Ord. \\
\hline Ruim & 24 & 1,9 & Sofrimento & 15 & 1,8 \\
\hline Sofrimento & 12 & 2,2 & Ruim & 9 & 1,5 \\
\hline Aprendizado & 5 & 2,4 & Saudade & 6 & 2,5 \\
\hline Saudade & 4 & 1,6 & Liberdade & 4 & 1,7 \\
\hline Adoecimento & 4 & 1,6 & Castigo & 4 & 2,0 \\
\hline Liberdade & 3 & 1,7 & - & - & - \\
\hline
\end{tabular}

Frequência > 2,5 e Classificação média > 2,5 $\quad$ Frequência $>$ 3,0 e Classificação média > 3,0

\begin{tabular}{cccccc}
\multicolumn{7}{c}{ G1 } & \multicolumn{7}{c}{ G2 } \\
\hline Enunciações & F & Ord. & Enunciações & F & Ord. \\
\hline Castigo & 4 & 2,6 & Rotina & 7 & 3,2 \\
Solidão & 4 & 2,8 & Família & 4 & 3,0 \\
Paciência & 4 & 2,8 & Medo & 4 & 3,7 \\
Fé & 3 & 3,0 & - & - & - \\
\hline \multicolumn{2}{c}{$3^{\circ}$ Quadrante }
\end{tabular}

Frequência < 2,5 e Classificação média $<$ 2,5 Frequência < 3,0 e Classificação média < 3,0

\begin{tabular}{cccccc} 
& G1 & \multicolumn{5}{c}{ G2 } \\
\hline Enunciações & F & Ord. & Enunciações & F & Ord. \\
\hline Escola & 2 & 1,7 & Difícil & 3 & 1,0 \\
Experiência & 2 & 2,0 & Aprendizado & 3 & 1,0 \\
Injustiça & 1 & 1,5 & Escola & 3 & 2,0 \\
- & - & - & Trabalhar & 3 & 2,5 \\
\hline & & & & continua...
\end{tabular}


...continuação

$$
4^{\circ} \text { Quadrante }
$$

Frequência < 2,5 e Classificação média > 2,5

Frequência < 3,0 e Classificação média > 3,0

\begin{tabular}{cccccc}
\multicolumn{7}{c}{ G1 } & \multicolumn{5}{c}{ G2 } \\
\hline Enunciações & F & Ord. & Enunciações & F & Ord. \\
\hline Violência & 2 & 3,0 & Paciência & 3 & 3,0 \\
Rotina & 1 & 2,5 & Adoecimento & 3 & 3,5 \\
Família & 1 & 2,5 & Solidão & 3 & 3,5 \\
Vida & 1 & 2,5 & Força & 3 & 3,5 \\
Erro & 1 & 3,0 & Parceria & 3 & 4,0 \\
Revolta & 1 & 3,5 & - & - & - \\
\hline
\end{tabular}

Nota. ${ }^{1}$ Frequência absoluta. ${ }^{2}$ Ordem média de classificação. O G1 é composto por internos em regime provisório e o G2 é composto por internos já sentenciados.

Tabela 2

Quadro geral de casas das evocações sobre o futuro em uma amostra de indivíduos em primeiro aprisionamento.

\begin{tabular}{|c|c|c|c|c|c|}
\hline \multicolumn{6}{|c|}{$1^{\circ}$ Quadrante } \\
\hline \multicolumn{3}{|c|}{ Frequência $>$ 2,5 e Classificação média < 2,5 } & \multicolumn{3}{|c|}{ Frequência $>$ 2,0 e Classificação média $<$ 2,0 } \\
\hline \multicolumn{3}{|c|}{ G1 } & \multicolumn{3}{|c|}{ G2 } \\
\hline Enunciações & $\mathbf{F}^{1}$ & Ord. ${ }^{2}$ & Enunciações & $\mathbf{F}$ & Ord. \\
\hline Família & 26 & 2,2 & Recomeço & 8 & 1,6 \\
\hline Trabalhar & 22 & 2,1 & Liberdade & 8 & 1,8 \\
\hline Liberdade & 7 & 1,4 & Estudar & 3 & 1,5 \\
\hline Vida & 7 & 2,0 & - & - & - \\
\hline Recomeço & 6 & 1,4 & - & - & - \\
\hline \multicolumn{6}{|c|}{$2^{\circ}$ Quadrante } \\
\hline \multicolumn{3}{|c|}{ Frequência > 2,5 e Classificação média > 2,5 } & \multicolumn{3}{|c|}{ Frequência > 2,0 e Classificação média > 2,0 } \\
\hline \multicolumn{3}{|c|}{ G1 } & \multicolumn{3}{|c|}{ G2 } \\
\hline Enunciações & $\mathbf{F}$ & Ord. & Enunciações & $\mathbf{F}$ & Ord. \\
\hline Tranquilidade & 11 & 3,0 & Vida & 22 & 2,5 \\
\hline Responsabilidade & 4 & 2,6 & Família & 17 & 2,1 \\
\hline Fé & 3 & 2,5 & Trabalhar & 15 & 2,3 \\
\hline- & - & - & Felicidade & 7 & 2,2 \\
\hline- & - & - & Honestidade & 3 & 2,0 \\
\hline
\end{tabular}

$3^{\circ}$ Quadrante

Frequência $<2,5$ e Classificação média $<$ 2,5 Frequência $<2,0$ e Classificação média $<2,0$

\begin{tabular}{cccccc}
\multicolumn{7}{c}{ G1 } & \multicolumn{5}{c}{ G2 } \\
\hline Enunciações & F & Ord. & Enunciações & F & Ord. \\
\hline Comprometido & 1 & 1,5 & Inocência & 2 & 1,0 \\
Melhoria & 1 & 1,5 & Sem drogas & 2 & 1,0 \\
Estudar & 1 & 2,0 & Fé & 2 & 1,0 \\
\hline
\end{tabular}


$4^{\circ}$ Quadrante

Frequência < 2,5 e Classificação média > 2,5

Frequência $<$ 2,0 e Classificação média $>$ 2,0

\begin{tabular}{cccccc}
\multicolumn{7}{c}{ G1 } & \multicolumn{7}{c}{ G2 } \\
\hline Enunciações & F & Ord. & Enunciações & F & Ord. \\
\hline Felicidade & 1 & 3,0 & Tranquilidade & 2 & 2,0 \\
Cuidado & 1 & 3,5 & Adaptação & 2 & 2,0 \\
- & - & - & Aposentar & 2 & 2,0 \\
- & - & - & Prosperidade & 2 & 3,0 \\
- & - & - & Força & 2 & 3,0 \\
- & - & - & Normal & 2 & 3,0 \\
- & - & - & Sabedoria & 2 & 4,0 \\
\hline
\end{tabular}

Nota. ${ }^{1}$ Frequência absoluta. ${ }^{2}$ Ordem média de classificação. O G1 é composto por internos em regime provisório e o G2 é composto por internos já sentenciados.

\section{Discussão}

No primeiro quadrante, que mostra os principais elementos evocados que compõem o núcleo central, as palavras que aparecem com maior frequência associadas ao termo indutor "prisão" foram similares, sendo elas "ruim" no G1 e "sofrimento" no G2, enquanto as palavras evocadas mais rapidamente no G1 foram "saudade" e "adoecimento", e no G2, foi a evocação "ruim".

As palavras evocadas com maior frequência pelos participantes dos dois grupos remetem à prisão como um lugar ruim e que causa sofrimento, demonstrando que o impacto do encarceramento é um evento negativo e traumático e que a prisão representa o começo de uma sucessão de estressores e dificuldades a serem enfrentados (Ruiz, 2007), principalmente na primeira experiência. Também é comum que presos recém-admitidos apresentem sofrimento psíquico durante certo tempo devido ao estresse do novo ambiente (Ahmad \& Mazlan, 2014), fato que se relaciona a esta pesquisa quando são consideradas as evocações "ruim" e "sofrimento", denotando que o ambiente estressor do presídio pode influenciar de forma negativa o processo de adequação e a adaptação dos internos em primeira custódia.

A partir dos resultados desta pesquisa, entendeu-se que a experiência do primeiro aprisionamento pode aumentar a vulnerabilidade do indivíduo ao adoecimento físico e mental, já que se foi caracterizada como algo predominantemente negativo nas principais evocações relacionadas à situação. Isso parece ser corroborado pelo que foi visto no G1, uma vez que a palavra "adoecimento" aparece entre as mais prontamente evocadas sobre a prisão.
O estudo de Araújo et al. (2009), com reclusos recém-chegados e antigos, também verificou que os internos novatos possuíam níveis mais significativos de depressão do que os demais, assim como foi constatado na pesquisa de Carvalho et al. (2016), em que os internos em regime provisório apresentaram níveis mais elevados de ansiedade do que os internos já condenados. No trabalho, Carvalho et al. (2016) estudaram a adaptação à vida na prisão, indicando que o indivíduo tem que interagir com o ambiente para torná-lo mais compatível com suas necessidades. Segundo os autores, no caso de uma inadequação no ajustamento do indivíduo ao ambiente penitenciário, problemas de adaptação e patologias podem surgir no aspecto emocional (ansiedade, tristeza, comprometimentos afetivos e agressividade), no somático (dores de cabeça e insônia), no cognitivo (problemas de concentração, atenção, memória e ruminação mental) e no social (comportamentos de confronto, inibição social, abuso de drogas e medicamentos ou ideações suicidas). Assim como no presente estudo, os achados dessas pesquisas corroboraram que os internos em primeiro encarceramento e em condição preventiva tendem a apresentar chances maiores de adoecimento durante a permanência na prisão.

No primeiro aprisionamento, além de lidar com os elementos estressores dentro da prisão, o custodiado precisa se desadaptar da vida pregressa e se adaptar à nova realidade de encarceramento ou condição de primeiro encarceramento, situação que pode explicar porque a palavra "saudade" fora prontamente evocada pelos internos do G1, o que provavelmente está associado à brusca ruptura dos laços familiares e à perda de contatos com a rede social (Ruiz, 2007). 
Em síntese, neste primeiro quadrante, tanto os participantes do G1 quanto do G2 relatam a prisão como um lugar de sofrimento e de saudade dos vínculos afetivos e da vida fora, já que tais conceitos foram os mais lembrados (em termos de quantidade e agilidade da menção). A palavra "liberdade" também foi evocada por G1 e G2, sugerindo que a expectativa de ver-se livre do ambiente hostil, controlador e de sofrimento da prisão independe da situação penal em que o interno se encontra no cárcere. A prisão foi abordada pelo Gl como um espaço de adoecimento e, consequentemente, desenvolvimento de problemas físicos e psicológicos durante a permanência. Dentre os conteúdos evocados pelo G2, a palavra "castigo" sugere que, para os participantes sentenciados a prisão se configurou como um ambiente ruim e de punição pelo erro cometido. Portanto, diante do impacto do aprisionamento, é natural que qualquer indivíduo deseje a liberdade e o retorno ao convívio social, afastando-se do constante sofrimento, adoecimento e saudade vivenciados no cárcere.

O segundo quadrante apresenta os elementos carregados de representações individuais, sendo suas evocações consideradas as mais importantes dentre as informações periféricas, devido à quantidade de vezes que foram recordadas (Sant'Anna, 2012). Nesse segundo quadrante, as palavras mais lembradas sobre a prisão pelos internos do G1 foram "castigo", "solidão", "paciência" e "fé", enquanto no G2 foram "família", "rotina" e "medo". Dentre as evocações do G1, a palavra "castigo" foi bem lembrada pelos participantes em primeiro encarceramento, uma vez que a prisão objetiva coibir a prática criminal e tem um caráter punitivo aos indivíduos que cometem infrações e adotam condutas desviantes (Barcinski \& Cunico, 2014). Sabe-se, ainda, que o impacto da privação de liberdade por si só já constitui um fator estressor, que adquire características distintas a depender do tipo de cumprimento de pena na prisão (Damas \& Oliveira, 2013); a prisão tem sido representada por muitos apenados como um "inferno" graças às condições precárias de vida e saúde ofertadas pelas unidades prisionais à sua população (Tavares \& Menandro, 2008). A tudo isso soma-se ainda a condição comum de superlotação nas unidades prisionais, fator que em nada favorece o retorno à vida em liberdade e a ressocialização dos indivíduos (Osasona \& Koleoso, 2015; Tavares \& Menandro, 2008).
Damas e Oliveira (2013) apontaram que as prisões brasileiras têm sido um espaço de aniquilamento das possibilidades de recuperação dos presos, visto que problemas de saúde podem ser adquiridos durante o aprisionamento. Ademais, os autores pontuam que com a precariedade do sistema prisional e a ausência de políticas públicas de acolhimento eficientes, observa-se o aumento de reincidências criminais. Desse modo, para os participantes do G1, a prisão evocada enquanto "castigo" pode estar atrelada às expectativas criadas quanto ao andamento do processo judicial e consequente liberdade, bem como ao sofrimento e adoecimento, também evocados no primeiro quadrante por este grupo.

Outra palavra evocada pelo G1 no segundo quadrante é "solidão", que também se relaciona com termo "saudade", evocado no primeiro quadrante. Afastados do convívio em sociedade e de suas relações sociais, a solidão se apresenta como um dos principais sentimentos que afetam os indivíduos encarcerados (Afonso, 2012). Em contrapartida, a palavra "paciência", evocada no segundo quadrante pelo Gl, pode ser entendida como uma menção à capacidade do apenado de tolerar as adversidades advindas do ambiente estressor do presídio, inclusive a falta de contato com as pessoas próximas.

A palavra "fé" foi uma das mais evocadas pelos participantes do G1 no segundo quadrante, o que pode ser visto de forma positiva, já que uma forma de aliviar as tensões e o estresse vivenciados na prisão é a prática religiosa. Estudos indicam que presidiários que possuem e praticam alguma religião são menos acometidos por desordens mentais de natureza depressiva em comparação com detentos que não têm religiosidade (Constantino et al., 2016; Pinese, Furegato, \& Santos, 2010). Oman e Thoresen (2005) sugeriram que os benefícios físicos da religião são frequentemente mediados por ganhos em saúde mental, tais como relações sociais e saúde melhoradas. Segundo os autores, o estado de saúde física, por sua vez, influencia os esforços para se manter a saúde mental. Assim sendo, a evocação "fé" sugere que os participantes do G1 empregam a religiosidade como uma estratégia de enfrentamento, na tentativa de minimizar o sofrimento e, consequentemente, os agravos à saúde mental.

Já no G2, a palavra "família" foi uma das mais evocadas, talvez por já se encontrarem julgados e em cumprimento de sentença condenatória na prisão, 
situação em que a proximidade da família pode ser decisiva para a saúde mental. Estudos em populações prisionais indicaram que a visita de familiares na prisão pode contribuir de forma positiva no ajustamento da pessoa presa e que, ao contrário, a falta dessa rede de apoio familiar e social produz agravos e aumento dos casos de tentativas de suicídio durante o aprisionamento (Afonso, 2012). Desse modo, a visita da família na instituição prisional provém o suporte social ao indivíduo e é um fator de proteção importante no processo de adaptação e na maneira como ele lidará com as adversidades do aprisionamento (Constantino et al., 2016; Pinheiro \& Cardoso, 2012).

O convívio da pessoa presa por meio das visitas prisionais é um direito garantido na Lei de Execução Penal (Lei $n^{\circ} 7210 / 1984$ ) para que, de certo modo, o interno tenha contato com o mundo externo à prisão (Cayres \& Sponchiado, 2015). No dia das visitas, a presença da família, além de permitir o acesso às informações da vida fora do presídio, também faz com que o apenado possa receber alimentação diferenciada da habitualmente oferecida pela instituição. Por isso, muitas vezes a suspensão das visitas familiares se configura uma das piores sanções aplicadas aos reclusos (Tavares \& Menandro, 2008).

Termos como "rotina" e "medo" também foram evocadas pelos participantes do G2, revelando não apenas um cotidiano moroso, mas também de apreensão. A rotina relatada pelos internos em primeira custódia evidencia a monotonia, o sedentarismo e a falta de atividades dentro da unidade prisional, fatores que podem ser psicologicamente estressantes (Osasona \& Koleoso, 2015). Além disso, todas as atividades são realizadas de forma sistemática e tudo é controlado pela instituição penal ou por outros detentos. Dentro do presídio, não é permitido ter iniciativas e nem há chances de privacidade (Colombaroli, 2013). O sentimento de medo vivenciado na prisão se relaciona à insegurança e desconfiança que paira na relação entre os próprios internos e a instituição penal. É improvável que a experiência de vida na prisão seja tranquila e agradável (Boothy \& Durham, 1999), especialmente para os reclusos em primeiro aprisionamento e que já se encontram condenados, visto que já não há mais esperança de alterações no processo judicial, restando somente o cumprimento em definitivo da sentença.

Em suma, no segundo quadrante os internos do G1 evocaram tanto palavras negativas (castigo e solidão) como positivas (paciência e fé). Os termos que compõem esse quadrante sugeriram que a vida na prisão é solitária e monótona, exigindo que os internos em primeiro aprisionamento tenham paciência para lidar com o ambiente estressor e limitador da prisão. Pode-se entender que a paciência e a fé, para o G1, foram utilizadas como estratégia de enfrentamento para lidar com as situações adversas que certamente ocorreram durante o aprisionamento. Para o G2 não é tão diferente, porém, a fé e a paciência dão lugar também à família como forma de equilíbrio e apoio para lidar com a rotina da prisão e com o impacto da privação de liberdade, além do medo de vivenciar a primeira experiência de encarceramento no sistema penitenciário. Ambos os grupos mostraram ter pontos de apoio que ajudam a lidar com a situação vivenciada, seja a família, seja a fé ou outra representação significativa. Entender esses pontos de suporte é importante, pois pode ajudar o profissional que lida diretamente com as pessoas em privação de liberdade a compreender o quanto o suporte familiar e social recebido no período do aprisionamento é fundamental para a proteção à saúde mental.

No terceiro quadrante aparecem as evocações que, apesar de serem muito relevantes, foram compartilhadas por um número menor de pessoas e, consequentemente, surgem em menor volume. Nesse quadrante é possível identificar novas evocações, temas e conteúdos presentes na prisão, usualmente compartilhadas por pequenos grupos, mas com alta primazia. O G1 aqui evocou "escola" e "injustiça" e, o G2, palavras como "escola" e "trabalhar", sendo o termo "escola", uma evocação em comum.

Neste quadrante, os participantes do G1 evocaram a palavra "injustiça" quando perguntados sobre o termo indutor "prisão". O sentimento de injustiça pode estar associado ao curto tempo de encarceramento nesse grupo (como visto na pesquisa, o tempo médio de aprisionamento foi de pouco mais de dez meses) e ao fato de ainda estarem detidos provisoriamente e aguardando $o$ andamento do processo judicial.

Como lembram Tavares e Menandro (2008), é improvável que os internos nutram representações positivas ou creiam na Justiça, o que se agrava com o regime provisório, já que há ainda a presunção de inocência, somado ao estigma que o tempo de permanência pode imprimir ao detento no retorno à sociedade (Mojica, Sáenz, \& Rey-Anacona, 2009; Ruiz, 2007). A possibilidade de aprisionamento injusto também pode impactar na saúde mental, provocando 
prejuízos psicológicos adicionais aos identificados no primeiro quadrante, em que a palavra "adoecimento" foi evocada por esse grupo. Quanto ao estigma, Goffman (1988) apontou que quando a estigmatização do indivíduo está atrelada à entrada na prisão, a maior parte do que o indivíduo aprende sobre o estigma será dentro da própria instituição, por meio da convivência íntima e prolongada com seus pares. Assim, ao sair da prisão, os egressos do sistema prisional tendem a se sentir inseguros por anteverem que o retorno à vida em liberdade pode ser permeado por dificuldades, com as consequentes repercussões negativas dessa marginalização na reinserção social.

A palavra "trabalhar", evocada pelos participantes do G2, pode evidenciar no contexto da prisão a falta de atividade laborativa, o que remete à ociosidade e ao tédio vivenciados diariamente pelos internos já sentenciados. De acordo com a literatura, o trabalho exercido durante o período de encarceramento tende a reduzir o acometimento de sintomatologias depressivas e torna-se um fator protetivo à saúde mental dos internos (Canazaro \& Argimon, 2010; Constantino et al., 2016). O trabalho na prisão também recria uma estrutura semelhante à que o interno vivenciará na vida fora da prisão e, portanto, também é auxiliador do processo de reinserção social (Carvalho et al., 2016)

A palavra "escola", evocada pelos dois grupos, apresenta outra caracterização dada à prisão pelos detentos, como um lugar onde é preciso aprender e se adaptar, o que inclui tentar aderir às regras e normas instituídas pela unidade prisional e por seus pares. Por ser considerada zona de contraste, $o$ terceiro quadrante indica o quão importante essa evocação é para ambos os grupos, pois, hipoteticamente, em algum momento futuro, essas evocações podem passar a ter maior destaque e, portanto, compor o primeiro quadrante (Sant'Anna, 2012).

No contexto da prisão, o termo "escola" recorda que no processo de adaptação à vida no cárcere a pessoa presa deve desaprender e se desfazer de hábitos e rotinas anteriores para se ajustar ao novo contexto (Afonso, 2012; Colombaroli, 2013). No processo de socialização ao meio prisional, o indivíduo precisará aprender uma série de regras de convivência que vão desde o modo de falar até como devem se comportar em um dia de visita (Barreto, 2006). Aos internos em primeira reclusão, também não são oferecidos cuidados diferenciados durante o encarceramento (Mojica et al., 2009), o que poderia prevenir reincidências na vida delituosa e o consequente retorno à prisão. A evocação "escola" também pode significar que o contato e convivência de apenados que cometeram crimes de menor potencial ofensivo com internos presos por delitos mais graves leve os apenados a assimilar os valores e regras de seus pares com o intuito de serem aceitos e se sentirem seguros no cárcere (Colombaroli, 2013).

No quarto quadrante aparecem as evocações que foram pouco frequentes no discurso dos internos e que também estão em menor quantidade. Nele, os elementos se apresentam de forma mais esparsa e difusa e o conteúdo evocado apresenta potencial de alterar o significado do objeto em questão, porém com menor força que os demais quadrantes (Sant'Anna, 2012). No G1 surgiram palavras como "rotina", "violência", "revolta" e "família", sugerindo que os participantes veem a vida na prisão como uma rotina de violência, revolta e/ou uma rotina de se esperar a família ou retorno ao convívio familiar. A vivência em um ambiente estressante e opressor cerca esses indivíduos de uma rotina de agressão e violência sofridas diariamente e que apresentam pouco potencial de mudança, uma vez que, inserido neste ambiente, só é dado ao interno a possibilidade de se adaptar às regras e à rotina imposta pela instituição penal e por seus pares (Afonso, 2012; Colombaroli, 2013; Gonçalves \& Gonçalves, 2012; Pinheiro \& Cardoso, 2011).

Já no G2 surgiram as palavras "adoecimento" e "paciência”, também evocadas pelo grupo dos provisórios (G1), respectivamente no primeiro e segundo quadrantes desta pesquisa sobre as evocações referentes ao termo indutor "prisão". Assim como no Gl, os participantes do G2 também precisarão ter tolerância e passividade para lidar com o ambiente adverso e estressor da prisão e, por consequência, também se encontram suscetíveis ao adoecimento por desajustes em seu processo de adaptação à primeira reclusão ou por desordens mentais comuns de natureza depressiva e ansiosa (Ahmad \& Mazlan, 2014; Araújo et al., 2009; Colombaroli, 2013; Constantino et al., 2016; Pinheiro \& Cardoso, 2011). Ademais, este mesmo grupo evocou palavras que evidenciaram que a prisão é um lugar ruim e de sofrimento (primeiro quadrante), mostrando mais uma vez a vulnerabilidade desses indivíduos ao adoecimento físico e mental durante o cumprimento da pena.

No último quadrante, o G1 trouxe algumas evocações não mencionadas pelo G2, como "violência", "erro", "revolta" e "vida", evidenciando a rotina de privações e violências sofridas no cárcere. Por outro lado, o G2 evocou palavras que focaram no adoecimento que a prisão 
e a solidão causam, porém, para esse grupo, a parceria com os colegas ameniza essa solidão e outorga força e paciência para continuar enfrentando a vida na prisão. As evocações desse quadrante, em geral, abarcaram sentidos relacionados às experiências ruins (erros e consequências negativas) e apresentaram novas formas de usar o tempo a seu favor (realizando e fortalecendo vínculos de amizade/parceria/família).

Sobre o termo indutor "futuro", no primeiro quadrante, dentre as palavras evocadas com maior frequência pelo G1 estão "família" e "trabalhar", e a mais prontamente evocada foi "recomeço". De acordo Tavares e Menandro (2008), quando se pergunta ao interno acerca do seu futuro, é a lembrança da família que emerge no discurso, mostrando o importante papel da família como fator de proteção significativo no processo de adaptação do interno ao ambiente prisional (Constantino et al., 2016; Pinheiro \& Cardoso, 2012), além de constituir um importante elemento de apoio social no processo de reinserção do egresso ao convívio em sociedade (Cayres \& Sponchiado, 2015).

Conforme Carvalho et al. (2016), é importante que ao sair da prisão o indivíduo também tenha a oportunidade de se inserir em um espaço de trabalho, bem como de estabelecer vínculos afetivos externos ao ambiente penitenciário. Na prisão, a atividade laborativa proporciona ao apenado uma oportunidade de estabelecer uma rotina semelhante à da vida em sociedade e um fator de proteção ao surgimento de doenças físicas e psicológicas (Canazaro \& Argimon, 2010; Carvalho et al., 2016; Constantino et al., 2016). Desse modo, talvez o futuro almejado ou pensado pelos participantes do G1 indique a expectativa de um recomeço de vida amparado pelo apoio familiar e do possível ingresso ou retorno ao mercado de trabalho, para sentirem-se reinseridos e aceitos socialmente.

No G2, as palavras evocadas com maior frequência foram "recomeço", "liberdade" e "estudar", sendo que esta última também foi a mais evocada, sugerindo que os participantes deste grupo almejam um futuro em liberdade e passível de recomeço por meio dos estudos. Nesta pesquisa, a maioria dos participantes do G2 cursaram até o ensino médio $(36,9 \%)$ e a média de idade foi de 34,3 anos. Portanto, o conteúdo evocado "estudar" pode indicar que a retomada dos estudos seria o veículo que promoveria seu recomeço de vida e consequente reinserção social. A palavra "recomeço" foi um termo evocado tanto no grupo dos provisórios (G1) quanto no grupo dos sentenciados (G2), sugerindo que ambos desejam uma nova oportunidade de recomeçarem suas vidas em liberdade, seja por meio do trabalho (G1), seja por meio dos estudos (G2).

No segundo quadrante do termo indutor "futuro", as palavras mais lembradas pelos internos do Gl foram "tranquilidade", "responsabilidade" e "fé". No G2, os termos evocados foram "família", "felicidade", "trabalhar" e "vida". No G1, as evocações sugerem que o futuro almejado pelos reclusos em primeira custódia seja tranquilo, responsável e permeado pela fé, talvez indicando o desejo de não vivenciar a experiência de encarceramento novamente. No G2, o conteúdo evocado evidenciou mais uma vez (primeiro quadrante) que a presença da família na vida do recluso pode ser um fator significativo para o alcance do sentimento de felicidade e demais objetivos a serem alcançados, por exemplo, a vontade de se reinserir socialmente por meio de uma oportunidade de trabalho. Assim, observou-se que, para ambos os grupos, o futuro após a experiência de primeiro encarceramento é interposto por perspectivas positivas de responsabilidade, família, felicidade, religiosidade através da expressão da fé e trabalho.

No terceiro quadrante constam as evocações que foram pouco frequentes nos discursos dos internos e, por isso, aparecem em menor volume. Tavares e Menandro (2008) pontuaram que o tempo vivido no cárcere pode comprometer as perspectivas e planejamento do futuro e, muitas vezes, os planos ficam no imaginário. No G1, algumas palavras que constituíram este quadrante foram "comprometido", "melhoria" e "estudar". Tais evocações sugerem que os internos podem pensar seu futuro com melhorias e com conquistas adquiridas por meio dos estudos. Já no G2, surgiram evocações como "sem drogas" e "fé". A menção a esses conteúdos pode indicar que as pessoas em primeiro aprisionamento almejam um futuro sem recaídas e com a presença de alguma religiosidade em suas vidas. A excludente realidade que envolve a vida de muitos internos custodiados no sistema penitenciário indica que, geralmente, os reclusos possuem baixa escolaridade, além de apresentarem problemas devido ao uso e/ou dependência de álcool e outras drogas (Barcinski \& Cúnico, 2014; Constantino et al., 2016). Portanto, ao passo que o G1 prospecta melhorar a vida ao sair da prisão retomando os estudos e vivendo de forma tranquila, o G2 almeja se manter afastado do uso de substâncias psicoativas e obter conforto e proteção, quando em liberdade, por meio da fé. 
Por fim, no quarto e último quadrante estão as evocações que foram pouco frequentes e que também constaram em menor quantidade no discurso dos internos. No G1, surgiram palavras como "felicidade" e "cuidado", as quais corroboram o conteúdo evocado por este mesmo grupo no quadrante anterior - o futuro com perspectivas melhores de vida e, consequentemente, com mais sentimento de felicidade e cuidado consigo e com os outros ao redor. Já no G2 surgiram evocações como "adaptação", "força", "tranquilidade" e "prosperidade", indicando que o desejo destes internos seja que a adaptação à vida em liberdade ocorra de maneira tranquila e próspera, e que haja força suficiente para enfrentar todas as adversidades e desafios que surgirem no retorno ao convívio social. Como visto, ambos os grupos manifestaram um discurso semelhante frente ao termo indutor "futuro", indicando que mesmo após a experiência de encarceramento, os reclusos ainda pensam seus futuros de maneira positiva. Ademais, as evocações obtidas corroboraram o conteúdo anteriormente apontado no primeiro quadrante sobre o futuro, evidenciando que o G1 e o G2 perceberam ser possível recomeçar suas vidas após o período de aprisionamento e, em específico, de primeiro aprisionamento.

\section{Considerações finais}

De modo geral, o conteúdo evocado sugeriu que ambos os grupos (G1 e G2) perceberam a "prisão" que foi o primeiro indutor de evocações - como um lugar difícil de se viver, de adoecimento e de intenso sofrimento físico e psicológico, visto que tais conteúdos foram muito lembrados pelos participantes. Porém, mesmo diante das dificuldades vivenciadas nesse ambiente, foi possível entender que a família, a religiosidade e o desempenho de atividade laborativa no cárcere podem ser fatores protetivos significativos, uma vez que também foram bastante lembrados na pesquisa. Quanto às evocações sobre o termo indutor "futuro", observou-se que os dois grupos apresentaram expectativas positivas para o recomeço de suas vidas em liberdade, tais como ter responsabilidade, sabedoria, fé, estar próximo da família e se sentir reinserido socialmente por meio do trabalho e dos estudos. Com tais conteúdos, procurou-se compreender os estressores e comportamentos adaptativos presentes no processo de adaptação do indivíduo em primeira reclusão no ambiente penitenciário.

Embora se tenha alcançado resultados interessantes, em virtude do tamanho amostral e do método de coleta por conveniência, é necessário ter cautela nas generalizações dos achados e conclusões do estudo. Outra limitação é o fato de que a pesquisa foi realizada em apenas uma instituição prisional, ou seja, questões relativas ao local em si podem ter afetado de alguma maneira as evocações dos sujeitos, como estar custodiado na prisão e fora da sua cidade e/ou estado de origem.

Finalmente, acredita-se que a partir do discurso evocado, profissionais da saúde e de áreas afins podem identificar fatores de risco e de proteção que deem suporte na atenção e cuidados prestados à saúde física e mental do interno, bem como auxiliar na identificação de desordens mentais comuns e problemas de adaptação à vida na prisão. Mesmo que desenvolvido com um grupo pequeno de internos, avalia-se que os conteúdos evocados foram relevantes para o conhecimento da percepção do apenado sobre sua experiência de primeiro encarceramento e perspectivas futuras. Diante disso, sugere-se que sejam realizadas novas pesquisas que visem compreender as experiências e a saúde mental da pessoa presa pela primeira vez, a fim de que esta parcela da população penitenciária tenha mais visibilidade no âmbito da saúde prisional e na elaboração de políticas públicas.

\section{Referências}

Afonso, L. P.V. (2012). Adaptaçãoà prisão:Estudo das relações entreos processos decoping, "marcadores"debem-estareajustamento psicológico [Tese de mestrado, Universidade de Minho]. RepositóriUM. http://hdl.handle.net/1822/24269

Ahmad, A., \& Mazlan, N. H. (2014). Stress and depression: A comparison study between men and women inmates in peninsular Malaysia. International Journal of Humanities and Social Science, 4(2), 153160.

Alves, R. F., \&Eulálio, M. C. (2011). Abrangência e níveis de aplicação da Psicologia da Saúde. In Alves, R. F. (Org.), Psicologia da saúde: Teoria, intervenção e pesquisa [online] (pp. 6588). EDUEPB. http://doi.org/10.7476/9788578791926

Araújo, F. A. F. M., Nakano, T. C., \& Gouveia, M. L. A. (2009). Prevalência de depressão e ansiedade em detentos. Avaliação Psicológica, 8(3), 381390. 
Psicologia: Ciência e Profissão 2021 v. 41 (n.spe 4), e217678,1-16.

Barcinski, M., \& Cunico, S. D. (2014). Os efeitos (in)visibilizadores do cárcere: As contradições do sistema prisional. Psicologia, 28(2), 6370. https://doi.org/10.17575/rpsicol.v28i2.696

Barreto, M. L. S. (2006). Depois das grades: Um reflexo da cultura prisional em indivíduos já libertos. Psicologia: Ciência e Profissão, 26(4), 582593. https://doi.org/10.1590/S1414-98932006000400006

Boothby, J. L., \& Durham, T. W. (1999). Screening for depression in prisoners using the Beck Depression Inventory. Criminal Justice and Behavior, 26, 107124. http:// doi.org/10.1177/0093854899026001006

Canazaro, D., \& Argimon, I. I. L. (2010). Características, sintomas depressivos e fatores associados em mulheres encarceradas no Estado do Rio Grande do Sul, Brasil. Cadernos de Saúde Pública, 26(7), 13231333. http:// doi.org/10.1590/S0102-311X2010000700011

Carr, D., \& Umberson, D. (2013). The social psychology of stress, health, and coping. In DeLamater, J., \& Ward, A. (Eds.), Handbook of Social Psychology (pp. 465490). Springer.

Carvalho, A. C., Lecat, B., \& Sendas, S. (2016). Detention conditions impact on anxiety and depression levels of prisoners. European Review of Applied Psychology, 66(4), 155162. http://doi.org/10.1016/j.erap.2016.05.002

Cayres, G. R. M., \& Sponchiado, V. B. Y. (2015). O direito de visita de crianças e adolescentes no sistema prisional brasileiro. Cadernos do Programa de Pós-Graduação em Direito - PPGDir/UFRGS, 10(3), 129147. https:// doi.org/10.22456/2317-8558.58851

Colombaroli, A. C. M. (2013, 25 de fevereiro). Efeitos sociológicos e psicológicos do cárcere. Diritto \& Diritti. https:// www.diritto.it/efeitos-sociologicos-e-psicologicos-do-carcere/

Constantino, P., Assis, S. G., \& Pinto, L. W. (2016). The impact of prisons on the mental health of prisoners in the state of Rio de Janeiro, Brazil. Ciência \& Saúde Coletiva, 21(7), 20892100. https://doi.org/10.1590/141381232015217.01222016

Cooper, C., \& Livingston, M. (1991). Depression and coping mechanismsin prisoner. Work \& Stress: An International Journal of Work, Health \& Organisations, 5(2), 149154. https://doi.org/10.1080/02678379108257011

Cozby, P. C. (2014). Métodos de pesquisas em ciências do comportamento. Atlas.

Damas, F., \& Oliveira, W. (2013). A saúde mental nas prisões de Santa Catarina, Brasil. Cadernos Brasileiros de Saúde Mental, 5(12), 124.

Ferrari, H. O., \& Lima, L.V. (2016). O uso de representações sociais como metodologia para avaliações diagnósticas. In V Congresso Brasileiro de Informática na Educação. Uberlândia, MG, Brasil. http:// dx.doi.org/10.5753/ cbie.wcbie.2016.487

Goffman, E. (1988). Estigma: Notas sobre a manipulação da identidade deteriorada. LTC.

Gois, S. M., Santos, H. P. O., Jr., Silveira, M. F. A., \& Gaudêncio, M. M. P. (2012). Beyond bars and punishments: A systematic review of prison health. Ciência \& Saúde Coletiva, 17(5), 12351246. http://doi.org/10.1590/S1413-81232012000500017

Gonçalves, L. C., \& Gonçalves, R. (2012). Agressividade, estilo de vida criminal e adaptação à prisão. Psicologia USP, 23(3), 559584. http://doi.org/10.1590/S0103-65642012005000013

López-Pérez B., Deeprose, C., \& Hanoch, Y. (2018). Prospective mental imagery as its link with anxiety and depression in prisoners. PLoS ONE, 13(3), 110. http://doi.org/10.1371/journal.pone.0191551

Marconi, M. A., \& Lakatos. E. M. (2003). Fundamentos de Metodologia Científica. Atlas.

Mojica, C., Sáenz, D., \& Rey-Anacona, C. A. (2009). Riesgo suicida, desesperanza y depresión en internos de un establecimiento carcelario colombiano. Revista Colombiana de Psiquiatría, 38(4), 681692.

Oman, D., \& Thoresen, C. E. (2005). Do religion and spirituality influence health? In Paloutzian, R. F., \& Park, C. L. (Eds.), Handbook of the psychology of religion and spirituality (pp. 435459). The Guilford Press.

Osasona, S. O., \& Koleoso, O. N. (2015). Prevalence and correlates of depression and anxiety disorder in a sample of inmates in a Nigerian prison. The International Journal of Psychiatry in Medicine, 50(2), 203218. http://doi.org/10.1177/0091217415605038

Pinese, C. S., Furegato, A. R., \& Santos, J. L. (2010). Demographic and clinical predictors of depressive symptoms among incarcerated women. Annals of General Psychiatry, 9(34), 17. http://doi.org/10.1186/1744-859X-9-34 
Pinheiro, I., \& Cardoso, J. (2011). Vulnerabilidade ao stress prisional e ao risco de suicídio na população reclusa: Estudo exploratório. Psiquiatria, Psicologia e Justiça, 12(4), 526.

Portaria GM/MS n.01, de 02 de janeiro de 2014 (2014, 3 janeiro). Aprova as normas de operacionalização financiamento da Política Nacional de Atenção Integral à Saúde no Sistema Prisional (PNAISP). Diário Oficial da União. http://bvsms.saude.gov.br/bvs/saudelegis/gm/2014/pri0001_02_01_2014.html

Remor, E. A. (1999). Psicologia da saúde: Apresentação, origem e perspectivas. Revista Psico de Porto Alegre, 30 (1), 205217.

Ruiz, J. (2007). Síntomas psicológicos, clima emocional, cultura y factores psicosociales em el medio penitenciario. Revista Latinoamericana de Psicología, 39(3), 547561.

Sant'Anna, H. C. (2012). OpenEvoc: Um programa de apoio à pesquisa em representações sociais. In L. Avelar, M. Ciscon-Evangelista, M. Nardi, A. Nascimento, \& P. Neto (Orgs.), Psicologia social: Desafios contemporâneos (pp. 94103). GM.

Santos, T. (Org.). (2017). Levantamento Nacional de Informações Penitenciárias: INFOPEN - Atualização de Junho de 2016. Departamento Penitenciário Nacional. https://www.conjur.com.br/dl/infopen-levantamento.pdf

Schultz, Á. L. V., Dias, M. T. G., Lewgoy, A. M. B., \& Dotta, R. M. (2017). Saúde no sistema prisional: Um estudo sobre a legislação brasileira. Argumentum, 9(2), 92107. https://doi.org/10.18315/argum..v9i2.15380

Schwarzer, R., \& Schulz, U. (2003). Stressful life events. In I. B. Weiner (Ed.), Handbook of psychology (pp. 2750). John Wiley \& Sons.

Tavares, G., \& Menandro, P. R. M. (2008). Trajetórias de vida de presidiários e possíveis sentidos para a prisão. Revista Psicologia Política, 8(15), 121138.

Uribe-Rodríguez, A. F., Martínez-Rodríguez, J. M., \& López-Romero, K. A. (2012). Depresión y ansiedad estado/ rasgo en internos adscritos al "Programa de Inducción al Tratamiento Penitenciario" en Bucaramanga, Colombia. Revista Criminalidad, 54(2), 4760.

\section{Milena de Andrade Bahiano}

Psicóloga Especialista em Saúde Mental (UFRJ) e Mestranda com bolsa Capes em Psicologia (PPGPSI) da Universidade Federal de Sergipe (UFS), São Cristóvão - SE. Brasil.

E-mail: millahandrade@hotmail.com

(1) https://orcid.org/0000-0003-2922-713X

\section{Geovanna Santana de Souza Turri}

Psicóloga Especialista em Gestão em Saúde pela Universidade Federal do Recôncavo da Bahia (UFRB) e Mestra em Psicologia Social pela UFS, Aracaju - SE. Brasil.

E-mail: geovannasantana92@gmail.com

(1) https://orcid.org/0000-0001-9493-5736

\section{André Faro}

Pesquisador produtividade CNPq (Nível 2). Doutor em Psicologia pela Universidade Federal da Bahia (UFBA) e docente do Programa de Pós-Graduação em Psicologia Social da UFS, São Cristóvão - SE. Brasil.

E-mail: andre.faro.ufs@gmail.com

(1) https://orcid.org/0000-0002-7348-6297

Endereço para envio de correspondência

Universidade Federal de Sergipe. Departamento de Psicologia. Avenida Marechal Rondon, s/n. Conjunto Rosa Elze. CEP: 49000-000. São Cristóvão - SE. Brasil.

Recebido $12 / 12 / 2018$

Aceito 29/07/2019 
Psicologia: Ciência e Profissão 2021 v. 41 (n.spe 4), e217678,1-16.

Received 12/12/2018

Approved 07/29/2019

Recibido 12/12/2018

Aceptado 29/07/2019

Como citar: Bahiano, M. A., Turri, G. S. S., \& Faro, A. (2021). A percepção da experiência de primeiro aprisionamento em uma unidade prisional. Psicologia: Ciência e Profissão, 41 (n.spe 4), 1-16. https://doi.org/10.1590/1982-3703003217678

How to cite: Bahiano, M. A., Turri, G. S. S., \& Faro, A. (2021). The perception of the experience of first imprisonment in a prison unit. Psicologia: Ciência e Profissão, 41 (n.spe 4), 1-16. https://doi.org/10.1590/1982-3703003217678

Cómo citar: Bahiano, M. A., Turri, G. S. S., \& Faro, A. (2021). La percepción de la experiencia de primer encarcelamiento en una unidad penitenciaria. Psicologia: Ciência e Profissão, 41 (n.spe 4), 1-16. https://doi.org/10.1590/1982-3703003217678 